\title{
Polymorphisms of the P-selectin gene and risk of myocardial infarction in men and women in the ECTIM extension study
}

F Kee, C Morrison, A E Evans, E McCrum, D McMaster, J Dallongeville, V Nicaud, O Poirier, F Cambien

\begin{abstract}
Background and objective-Studies in animal models and humans implicate cell adhesion molecules in atherogenesis but their role in mediating the risk of myocardial infarction is unclear. The ECTIM (étude cas-temoin de l'infarctus myocarde) extension study was established to determine whether a previously implicated polymorphism of the P-selectin gene was associated with myocardial infarction risk in men and women in Belfast and Glasgow.

Patients and study setting-696 cases with a recent myocardial infarction and 561 age matched controls (both male and female) were recruited into a case-control study in MONICA project areas of Belfast and Glasgow.

Methods-Demographic and lifestyle information was collected by interview administered questionnaire, and each subject was examined and provided a blood sample for DNA extraction. The polymerase chain reaction (PCR) was used to amplify regions encompassing the P-selectin $\mathrm{Thr} \rightarrow$ Pro $(\mathrm{A} / \mathrm{C})$ polymorphism at position 715 . Genotype odds ratios for myocardial infarction were estimated by logistic regression adjusted for population, age, and sex.

Results-There was no significant association between conventional risk factors (such as hypercholesterolaemia, increased body mass index, or raised blood pressure) and either the rare or the common Pro ${ }^{715}$ allele of the P-selectin gene in controls. Overall, comparing Pro ${ }^{715} /$ Pro $^{715}$ and $\mathrm{Pro}^{715} / \mathrm{Thr}^{715}$ with $\mathrm{Thr}^{715} / \mathrm{Thr}^{715}$, with adjustment for centre, age, and sex, the odds ratio was 0.78 (95\% confidence interval 0.60 to 1.00$)(p=0.054)$, indicating a "protective" effect of the less common Pro $^{715}$ allele. There was no significant heterogeneity in odds ratios between men and women either in this sample or when combined with the original ECTIM subjects.

Conclusions-In a large population based study in two regions of the UK, we have been able to corroborate the earlier ECTIM findings of a lower frequency of the Thr/Pro ${ }^{715}$ polymorphism in subjects with myocardial infarction. An apparently "protective effect" of similar magnitude also seems to apply to women.

(Heart 2000;84:548-552)
\end{abstract}

Keywords: P-selectin; cell adhesion molecules; atherogenesis

Adhesion of circulating leucocytes to the endothelial lining is an early event in the atherosclerotic process. A variety of cell adhesion molecules is involved in a cascade of events which result in the infiltration of leucocytes and monocytes into the evolving plaque. While the expression of some of these adhesion molecules may only be transitory, studies in transgenic mice deficient in one or other of the relevant genes confirm their contributory role in the extent and content of plaques. ${ }^{1}$

The precise role of these molecules in humans and the variation in the genes responsible has yet to be determined. In 1996, Wenzel and colleagues ascertained the frequency of specific polymorphism of E-selectin, L-selectin, and ICAM-I (intercellular adhesion molecule) in 99 patients under 50 years of age with severe angiographically proven coronary artery disease, and compared this with the frequency in 100 volunteer controls. ${ }^{2}$ Exchanges in the E-selectin gene from serine to arginine (position 128), from leucine to phenylalanine (position 554), and from guanine to thymine (position 98) were more frequent in cases than in controls. Because of the small numbers of cases involved, the authors were unable to report on or adjust for any potential associations with intermediate traits such as hypercholesterolaemia, body mass index (BMI), or hypertension.

Subsequently, the larger ECTIM study (étude cas-temoin de l'infarctus myocarde) investigated 13 polymorphism of the $\mathrm{P}$-selectin gene in 647 male cases with myocardial infarction and 758 controls from four regions of France and Northern Ireland. ${ }^{3}$ The Pro ${ }^{715}$ allele was less frequent in France than in Northern Ireland $(0.107 v 0.174)$ and in cases compared with controls (for example, $0.98 v 0.174$ in Belfast). No independent associations were shown with blood pressure, BMI, or lipid concentrations. These findings have not yet been corroborated in other studies.

A major strength of ECTIM has been its recruitment of subjects from areas with a threefold differential in coronary attack rates, but until now fewer previous studies in this field have recruited women. The ECTIM extension study was undertaken in Belfast and Glasgow with this purpose in mind and afforded us with the opportunity to investigate the role of a P-selectin polymorphism which may modify the risk of myocardial infarction in these populations. 
Table 1 ASO sequences and hybridisation conditions

\begin{tabular}{lllll}
\hline & Sequence & Tm $\left({ }^{\circ} \mathrm{C}\right)$ & Hybridisation & $\begin{array}{l}\text { Last } \\
\text { washing }\end{array}$ \\
\hline M & 5'ACTGGTCAACTACCGTG 3' & 52 & 47 & 49 \\
W & 5'ACTGGTCACCTACCGTG 3' & 54 & 49 & 51 \\
\hline
\end{tabular}

\section{Methods}

The sampling frames for both countries were based upon the catchment areas for the local MONICA (monitoring trends and determinants of cardiovascular disease) project registers. In Northern Ireland, the register covered the greater Belfast and North Down areas, a population of around 500 000. In Glasgow the MONICA register served a population of around 900 000. Male cases between the ages of 25-64 years were recruited between three and nine months after the index infarction. Recruitment procedures for female cases in Glasgow were exactly the same as for men but because of the much smaller population base and lower incidence, female subjects in Belfast aged 25-69 years were enrolled up to two years after their infarction. Controls of comparable age ( \pm one year) were recruited from random samples generated from the lists of general practitioners in the same area.

Each participant completed an interview administered demographic and lifestyle questionnaire including sections dealing with smoking and alcohol habits and past medical history. This questionnaire closely reflected that used in the original ECTIM study but had an additional section for women to identify the subject's menopausal status. Height was recorded using a stadiometer, and BMI calculated. Blood pressure was recorded using a random zero sphygmomanometer.

A blood sample of $20 \mathrm{ml}$ was obtained after subjects had fasted for at least 10 hours, placed in tubes containing sodium-EDTA, kept at room temperature, and centrifuged within four hours. The Institut Pasteur in Lille subsequently measured cholesterol in the very low density lipoprotein (VLDL) fraction separated by ultracentrifugation ${ }^{4}$ and in the high density lipoprotein (HDL) containing supernatant after sodium phosphotungstate/magnesium chloride precipitation (Boehringer Mannheim,
Mannheim, Germany). Low density lipoprotein (LDL) cholesterol was estimated by subtraction.

Genomic DNA was prepared from white blood cells by Miller's salting out method. ${ }^{5}$ The polymerase chain reaction (PCR) was used to amplify regions encompassing the P-selectin $\mathrm{Thr} \rightarrow$ Pro (A/C) polymorphism at position 715. Genotyping was performed using allele specific oligonucleotides, as previously described. ${ }^{3}$

The ASO sequences and the hybridisation conditions are shown in table 1 .

Genotype and allele frequencies were initially compared by $\chi^{2}$ analysis. Genotype odds ratios for myocardial infarction were estimated by logistic regression adjusted for population, age, and sex. Associations with conventional risk factors were tested by analysis of variance, adjusted for age, sex, and menopausal status in women. Non-normally distributed variables (triglyceride concentrations) were first log transformed.

Informed consent was given by all subjects for DNA extraction. The study was approved by the research ethics committee of the Faculty of Medicine, the Queen's University of Belfast, and by the equivalent ethics committee in Glasgow.

\section{Results}

In total, 201 female cases and 194 female controls were newly recruited in Belfast. An additional 100 male cases and 82 controls were also enrolled. In Glasgow, 291 male and 104 female cases were recruited, along with 274 and 97 controls.

As approximately six years elapsed between the original study and recruitment of the additional subjects, some comparison of their characteristics is warranted. These are summarised in tables 2 and 3.

The male and female controls in the extension are significantly older than the controls (males) in the original ECTIM sample, by roughly four and seven years respectively. The difference between the male cases, however, was only 1.5 years. Among the male cases the smoking prevalence was $19 \%$

Table 2 Comparison of sociodemographic characteristics of cases and controls in Northern Ireland

\begin{tabular}{|c|c|c|c|c|c|c|c|c|}
\hline \multirow[b]{2}{*}{ Characteristic } & Case & Control & \multirow[b]{2}{*}{$\begin{array}{l}p \text { Value } \\
(1 \vee v 2)\end{array}$} & \multirow{2}{*}{$\begin{array}{l}\text { Case } \\
\begin{array}{l}\text { Female (3) } \\
(n=201)\end{array}\end{array}$} & \multirow{2}{*}{$\begin{array}{l}\text { Control } \\
\begin{array}{l}\text { Female (4) } \\
(n=194)\end{array}\end{array}$} & \multirow[b]{2}{*}{$\begin{array}{l}p \text { Value } \\
(3 v 0)\end{array}$} & \multirow[b]{2}{*}{$\begin{array}{l}p \text { Value } \\
(1 v 3)\end{array}$} & \multirow[b]{2}{*}{$\begin{array}{l}p \text { Value } \\
(2 v 4)\end{array}$} \\
\hline & $\begin{array}{l}\text { Male (1) } \\
(n=100)\end{array}$ & $\begin{array}{l}\text { Male (2) } \\
(n=82)\end{array}$ & & & & & & \\
\hline Mean age (years) & 56.1 & 59.1 & 0.005 & 61.6 & 62.2 & 0.42 & $<0.0001$ & $<0.0001$ \\
\hline \multicolumn{9}{|l|}{ Social class $(\%)$} \\
\hline Non-manual & 31.0 & 53.7 & \multirow[t]{2}{*}{$<0.002$} & 32.0 & 54.2 & \multirow[t]{2}{*}{$<0.0001$} & \multirow[t]{2}{*}{0.87} & \multirow[t]{2}{*}{0.93} \\
\hline Manual & 69.0 & 46.3 & & 68.0 & 45.8 & & & \\
\hline \multicolumn{9}{|l|}{ Smoking (\%) } \\
\hline Smokers & 37.0 & 19.8 & \multirow[t]{3}{*}{$<0.03$} & 48.8 & 22.0 & \multirow[t]{3}{*}{$<0.0001$} & \multirow[t]{3}{*}{0.05} & \multirow[t]{3}{*}{$<0.0001$} \\
\hline Ex-smokers & 33.0 & 45.7 & & 20.9 & 18.8 & & & \\
\hline Non-smokers & 30.0 & 34.6 & & 30.3 & 59.2 & & & \\
\hline \multicolumn{9}{|l|}{ Alcohol (\%) } \\
\hline None & 39.0 & 32.9 & \multirow[t]{4}{*}{0.60} & 70.6 & 68.0 & \multirow[t]{4}{*}{0.32} & \multirow[t]{4}{*}{$<0.0001$} & \multirow[t]{4}{*}{$<0.0001$} \\
\hline Light & 35.0 & 43.9 & & 27.9 & 32.0 & & & \\
\hline Moderate & 16.0 & 12.2 & & 1.0 & 0.0 & & & \\
\hline Heavy & 10.0 & 11.0 & & 0.5 & 0.0 & & & \\
\hline On lipid treatment (\%) & 29.0 & 11.0 & $<0.003$ & 37.3 & 13.9 & $<0.0001$ & 0.15 & 0.51 \\
\hline Mean BMI & 26.2 & 26.8 & 0.33 & 27.1 & 25.9 & 0.02 & 0.11 & 0.16 \\
\hline $\begin{array}{l}\text { Treated for hypertension } \\
(\%)\end{array}$ & 33.0 & 17.1 & 0.01 & 33.3 & 23.2 & 0.02 & 0.95 & 0.26 \\
\hline
\end{tabular}

BMI, body mass index $\left(\mathrm{kg} / \mathrm{m}^{2}\right)$. 
Table 3 Comparison of sociodemographic characteristics of cases and controls in Glasgow

\begin{tabular}{|c|c|c|c|c|c|c|c|c|}
\hline & Case & Control & & Case & Control & & & \\
\hline Characteristic & $\begin{array}{l}\text { Male (1) } \\
(n=291)\end{array}$ & $\begin{array}{l}\text { Male (2) } \\
(n=274)\end{array}$ & $\begin{array}{l}p \text { Value } \\
(1 \quad v 2)\end{array}$ & $\begin{array}{l}\text { Female (3) } \\
(n=104)\end{array}$ & $\begin{array}{l}\text { Female (4) } \\
(n=97)\end{array}$ & $\begin{array}{l}p \text { Value } \\
(3 v 4)\end{array}$ & $\begin{array}{l}p \text { Value } \\
(1 \quad v 3)\end{array}$ & $\begin{array}{l}p \text { Value } \\
(2 v 4)\end{array}$ \\
\hline Mean age (years) & 54.5 & 54.8 & 0.71 & 57.3 & 58.1 & 0.40 & 0.001 & $<0.0001$ \\
\hline \multicolumn{9}{|l|}{ Social class (\%) } \\
\hline Non-manual & 20.6 & 29.6 & \multirow[t]{2}{*}{0.01} & 27.3 & 48.5 & \multirow[t]{2}{*}{0.002} & \multirow[t]{2}{*}{0.22} & \multirow[t]{2}{*}{0.001} \\
\hline Manual & 79.4 & 70.4 & & 72.7 & 51.5 & & & \\
\hline \multicolumn{9}{|l|}{ Smoking (\%) } \\
\hline Smokers & 59.2 & 40.1 & \multirow{3}{*}{$<0.0001$} & 76.5 & 38.1 & \multirow[t]{3}{*}{$<0.0001$} & \multirow[t]{3}{*}{0.01} & \multirow{3}{*}{0.25} \\
\hline Ex-smokers & 26.5 & 33.2 & & 12.7 & 26.8 & & & \\
\hline Non-smokers & 14.3 & 26.6 & & 10.8 & 35.1 & & & \\
\hline \multicolumn{9}{|l|}{ Alcohol (\%) } \\
\hline None & 28.0 & 17.9 & \multirow[t]{4}{*}{0.02} & 64.9 & 34.0 & \multirow[t]{4}{*}{$<0.0001$} & \multirow[t]{4}{*}{$<0.0001$} & \multirow[t]{4}{*}{$<0.0001$} \\
\hline Light & 31.5 & 35.0 & & 32.0 & 60.8 & & & \\
\hline Moderate & 20.8 & 28.5 & & 3.1 & 5.2 & & & \\
\hline Heavy & 19.7 & 18.6 & & 0.0 & 0.0 & & & \\
\hline On lipid treatment $(\%)$ & 34.4 & 6.2 & $<0.0001$ & 35.6 & 7.2 & $<0.0001$ & 0.92 & 0.91 \\
\hline Mean BMI & 27.9 & 27.0 & 0.02 & 28.2 & 27.7 & 0.49 & 0.63 & 0.26 \\
\hline $\begin{array}{l}\text { Treated for } \\
\text { hypertension }(\%)\end{array}$ & 40.3 & 17.5 & $<0.0001$ & 38.5 & 23.7 & 0.02 & 0.84 & 0.24 \\
\hline
\end{tabular}

BMI, body mass index $\left(\mathrm{kg} / \mathrm{m}^{2}\right)$.

lower in the extension sample. Although there was only a small increase in the proportion of cases receiving lipid lowering treatment at the time of recruitment (from $27.5 \%$ to $29 \%$ ), the numbers of controls under treatment had also increased (from $9 \%$ to $12.5 \%$ ). There was also a material increase in the proportion of cases receiving treatment for hypertension (from $19 \%$ to $33 \%$ ), which was to some extent evident for controls as well (from $13 \%$ to $17.1 \%)$. Twice as many female and male controls in Belfast were on lipid lowering drugs compared with their Glasgow counterparts ( $13.9 \% v 7.2 \%$, and $11 \% v 6.6 \%$, respectively). The frequency of alcohol abstention in controls was also lower in Glasgow than in Belfast $(17.9 \%$ v $32.9 \%$ in men).

COMPARISON OF GENOTYPES

The alleles of the P-selectin $\mathrm{Thr} \rightarrow$ Pro $(\mathrm{A} / \mathrm{C})$ polymorphism were in Hardy-Weinberg equilibrium. There were no significant associations between any of the conventional risk factors and the three genotype classes, although when the ECTIM extension subjects were supplemented with the original sample from the first Belfast ECTIM study (data not shown), subjects homozygous for the Thr $\rightarrow$ Pro polymorphism had a greater BMI (27.98 v $25.96 \mathrm{~kg} / \mathrm{m}^{2}$ ) but overall these homozygotes had a lower systolic blood pressure (127.9 v $133.4 \mathrm{~mm} \mathrm{Hg}$ ).

Table 4 shows the association between genotypes and case-control status in both men and women in the ECTIM extension. There was no significant difference in genotype frequencies among controls from Belfast and Glasgow. Adjusted for centre and age, the genotype odds ratios for men and women were $0.83(95 \%$ confidence interval (CI) 0.59 to 1.16 ) and 0.71 (95\% CI 0.48 to 1.07 ), respectively. Overall, comparing $\mathrm{Pro}^{715} / \mathrm{Pro}^{715}$ and $\mathrm{Pro}^{715} / \mathrm{Thr}^{715}$ with $\mathrm{Thr}^{715} / \mathrm{Thr}^{715}$, with adjustment for centre, age, and sex, the odds ratio was 0.78 (95\% CI 0.60 to 1.00$)(p=0.054)$, indicating a "protective" effect of the less common allele. There was no significant heterogeneity across centres or between sexes, but the effect was significant in the Belfast sample alone.

\section{Discussion}

In a large population based study in two regions of the UK, we have been able to corroborate the earlier ECTIM findings of a lower frequency of the less common allele $\left(\mathrm{Pro}^{715}\right.$ ) of the $\mathrm{Thr} / \mathrm{Pro}^{715}$ polymorphism in subjects with myocardial infarction. This protective effect is comparable in men and women.

A study with 610 subjects/group should have had at least $85 \%$ power (with an $\alpha$ error of $5 \%$ ) to detect an odds ratio of 0.67 , given the

Table 4 Odds ratios for myocardial infarction across $P$-selectin Pro ${ }^{75}$ genotypes in the ECTIM extension

\begin{tabular}{|c|c|c|c|c|c|c|c|c|c|c|c|c|}
\hline & \multicolumn{4}{|c|}{ Belfast } & \multicolumn{4}{|c|}{ Glasgow } & \multicolumn{4}{|l|}{ All } \\
\hline & \multicolumn{2}{|l|}{ Cases } & \multicolumn{2}{|c|}{ Controls } & \multicolumn{2}{|l|}{ Cases } & \multicolumn{2}{|c|}{ Controls } & \multicolumn{2}{|l|}{ Cases } & \multicolumn{2}{|c|}{ Controls } \\
\hline & $n$ & $\%$ & $n$ & $\%$ & $n$ & $\%$ & $n$ & $\%$ & $n$ & $\%$ & $n$ & $\%$ \\
\hline \multicolumn{13}{|l|}{ Men } \\
\hline $\mathrm{Thr} / \mathrm{Thr}^{715}$ & 77 & 77.8 & 56 & 69.1 & 203 & 74.4 & 186 & 72.4 & 280 & 75.3 & 242 & 71.6 \\
\hline $\mathrm{Thr} / \operatorname{Pro}^{715}$ & 21 & 21.2 & 23 & 28.4 & 68 & 24.9 & 68 & 26.5 & 89 & 23.9 & 91 & 26.9 \\
\hline Pro/Pro ${ }^{715}$ & 1 & 1.0 & 2 & 2.5 & 2 & 0.7 & 3 & 1.2 & 3 & 0.8 & 5 & 1.5 \\
\hline Odds ratio* & \multicolumn{4}{|c|}{$0.64(0.33$ to 1.25$)$} & \multicolumn{4}{|c|}{$0.9(0.61$ to 1.33$)$} & \multicolumn{4}{|c|}{$0.83(0.59$ to 1.16$)$} \\
\hline \multicolumn{13}{|l|}{ Women } \\
\hline $\mathrm{Thr} / \mathrm{Thr}^{715}$ & 152 & 80.4 & 141 & 73.8 & 80 & 82.5 & 70 & 78.7 & 232 & 81.1 & 211 & 75.4 \\
\hline $\mathrm{Thr} / \operatorname{Pro}^{715}$ & 33 & 17.5 & 47 & 24.6 & 16 & 16.5 & 17 & 19.1 & 49 & 17.1 & 64 & 22.9 \\
\hline Pro/Pro ${ }^{715}$ & 4 & 2.1 & 3 & 1.6 & 1 & 1.0 & 2 & 2.2 & 5 & 1.7 & 5 & 1.8 \\
\hline Odds ratio* & \multicolumn{4}{|c|}{$0.69(0.42$ to 1.11$)$} & \multicolumn{4}{|c|}{$0.78(0.38$ to 1.62$)$} & \multicolumn{4}{|c|}{$0.71(0.48$ to 1.06$)$} \\
\hline \multicolumn{13}{|l|}{ All } \\
\hline $\mathrm{Thr} / \mathrm{Thr}^{715}$ & 229 & 79.5 & 197 & 72.4 & 283 & 76.5 & 258 & 74.1 & 512 & 77.8 & 455 & 73.4 \\
\hline $\mathrm{Thr} / \operatorname{Pro}^{715}$ & 54 & 18.8 & 70 & 25.7 & 84 & 22.7 & 85 & 24.4 & 138 & 21.0 & 155 & 25.0 \\
\hline Pro/Pro ${ }^{715}$ & 5 & 1.7 & 5 & 1.8 & 3 & 0.8 & 5 & 1.4 & 8 & 1.2 & 10 & 1.6 \\
\hline Odds ratio* & \multicolumn{4}{|c|}{$0.68(0.46$ to 1.00$)$} & \multicolumn{4}{|c|}{$0.88(0.63$ to 1.24$)$} & \multicolumn{4}{|c|}{$0.79(0.61$ to 1.02$)$} \\
\hline
\end{tabular}

*With $95 \%$ CI. 
frequency of Pro/Pro and Pro/Thr (30\%) and the magnitude of the protective effect (odds ratio 0.67 ) found in the first ECTIM study. ${ }^{3}$ If we were to combine the present findings with those from the first study, the combined odds ratio would be 0.73 (95\% CI 0.58 to 0.92 ) overall, and 0.73 (95\% CI 0.56 to 0.96 ) and $0.71(95 \%$ CI 0.48 to 1.06$)$ in men and women, respectively. We recruited women up to two years after their myocardial infarction and up to nine months for men. We do not believe that this biases the findings materially from selective mortality, as nearly $90 \%$ of the mortality from myocardial infarction occurs in the first 28 days after the attack. ${ }^{6}$

There has been growing interest in the role of cellular adhesion molecules in atherogenesis. $\mathrm{P}$-selectin is an integral membrane glycoprotein of platelet $\alpha$ granules and the membrane component of the Weibel-Palade bodies of endothelial cells, the organelle which stores von Willebrand factor. It is known that in vitro it is important for maintaining the nonadhesiveness of neutrophils in the circulation and for inhibiting superoxide generation. However, the biological significance of soluble $\mathrm{P}$-selectin in vivo is unclear. Most previous studies have either dealt with animal models ${ }^{7}$ or with variations in the expressed proteins in different human conditions, including coronary artery spasm and postangioplasty restenosis. ${ }^{8-11}$

Drawing broader conclusions has been a challenge, as various phenotypes-reflecting different parts of the atherosclerotic disease process and its outcomes-have been the focus of these studies. Also, most of the studies have been conducted in men. No doubt the objectives of these studies involve the better identification of subjects at risk of the disease or the clarification of the in vivo significance of the action of adhesion molecules, with a view to devising new therapeutic targets. It is possible that what has been observed in some previous studies is the altered expression of these molecules consequent upon the disease process. Our study, however, points to the possible functional significance of $\mathrm{P}$-selectin in defining the risk of infarction.

Two caveats must be born in mind. First, given the high mortality within the first three months after a myocardial infarction, it cannot be excluded that the Pro ${ }^{715}$ allele is associated with an increased mortality. However, we did not show any differences in odds ratio in low or high risk cases, defined in a variety of ways on the basis of their BMI, lipid concentrations, or smoking habits (data not shown). Also we found scant evidence of major associations with conventional risk factors, although the higher BMI and lower systolic blood pressure in men with the rarer allele remains unexplained. Second, the true functional significance of this polymorphism is unknown. The original ECTIM report could not exclude the possibility that this allele was not solely responsible for the apparent protective effect. Rather, particular haplotypes involving the Pro $^{715}$ change or another functional mutation in linkage disequilibrium, may have more significance. The Pro ${ }^{715}$ polymorphism lies in the tandem repeat domain. Maulaud and colleagues have recently been able to show that the in vivo and in vitro application of a monoclonal antibody against the CD4 domain of P-selectin gives rise to reduced adhesion activity, suggesting that the tandom repeat domain may play a functional role in P-selectin-leucocyte interactions. $^{12}$

Within a couple of years the human genome will have been sequenced. While it may then be possible to distinguish functional from nonfunctional variants, the problems of accurately defining risk in populations, taking account of the many possible gene-gene and geneenvironment interactions, will have reached a new level of complexity.

1 Dong MZ, Chapman SM, Brown AA, et al. The combined ole of $\mathrm{P}$ and $\mathrm{E}$ selectins in atherosclerosis. 7 Clin Invest 1998;102:145-52.

2 Wenzel K, Ernst M, Rhode K, et al. DNA polymorphism in adhesion molecule genes - a new risk factor for early atherosclerosis. Hum Genet 1996;97:15-20.

3 Herrmann S-M, Ricard S, Nicaud V, et al. The P-selectin gene is highly polymorphic: reduced frequency of the Pro715 allele carriers in patients with myocardial infarction. Hum Mol Genet 1998;7:1277-84.

4 Alaupovic P, Lee DM, McConathy WJ. Studies on the composition and structure of plasma lipoproteins: distribution of lipoprotein families in major density classes of normal human plasma lipoproteins. Biochim Biophys Acta 1972; 260:689-707.

5 Miller SA, Dykes DD, Poleski HF. Simple salting out procedure for extracting DNA from human nucleated cells. dure for extracting DNA from
Nucleic Acid Res 1988;16:1215.

6 Evans AE, Patterson CC, Mathewson Z, et al. Incidence, delay and survival in the Belfast MONICA project coronary event register. Rev Epidemiol Sante Publ 1990;38: $419-27$

7 Kumar A, Hoover J, Simmons CA, et al. Remodelling and neointimal formation in the carotid artery of normal and P-selectin deficient mice. Circulation 1997;96:4333-42.

8 Kaikita K, Ogawa H, Yasue H, et al. Soluble P-selectin is released into the coronary artery circulation after coronary spasm. Circulation 1995;92:1726-30.

9 Ishiwata S, Tukada T, Nakanishi S, et al. Post angioplasty restenosis: platelet activation and the coagulation fibrinolysis system as possible factors in the pathogenesis of restenosis. Am Heart f 1997;133:387-92.

10 Peter K, Nawroth P, Conradt C, et al. Circulating vascular cell adhesion molecule-I correlates with the extent of human atherosclerosis in contrast to circulating adhesion molecule I, E-selectin, P-selectin and thrombomodulin. Arterioscler Thromb Vasc Biol 1997;17:505-12.

11 Blann AD, Faragher EB, McCollum CN. Increased soluble P-selectin following myocardial infarction: a new marker for progression of atherosclerosis. Blood Coagul Fibrinolysis for progression of

12 Maulaud E, Chignier E, Buckland R, et al. Identification of functional site (amino acids 412-416) on the complement like repeat domains implicated in P-selectin (CD62P) leukocyte interactions [abstract]. Thromb Haemost 1997; 78(suppl):A333.

\section{Commentary}

P-selectin is one of many "adhesion molecules" that mediate the interaction between vascular endothelium and activated neutrophils and platelets. Adhesion molecules like P-selectin are implicated in many vascular disease processes including atherosclerosis and vascular remodelling following angioplasty. The gene encoding for P-selectin is highly polymorphic-that is, 13 different forms of the gene (alleles), determined by small variations in the DNA sequence, are present in the population. Previous work with patients enroled in the ECTIM study suggested that one polymorphism, Thr715Pro (Thr/Pro ${ }^{715}$ ), was more common in France than in Northern Ireland and was associated with reduced risk of myocardial infarction. The present casecontrol study extends upon that work by examining the frequency of this putative protective polymorphism of the $\mathrm{P}$-selectin gene 
in a larger cohort of both women and men from Belfast and Glasgow. The principal finding (which is marginally significant at $\mathrm{p}=0.054$ ), that the Thr715Pro polymorphism occurs at a lower frequency in subjects who have had a myocardial infarction, supports the notion that this allele may contribute to a "protected phenotype" in both men and women. Hopefully, the next few years will build on relatively small studies such as this and provide more extensive insights into the undoubtedly complex role that genotype plays in the development of ischaemic heart disease.

G F BAXTER Associate Editor

\section{IMAGES IN CARDIOLOGY}

\section{How to survive myocardial rupture after myocardial infarction}

A 79 year old woman was admitted to hospital because of acute, severe chest pain of 12 hours' duration. She had known coronary three vessel disease with prior coronary artery bypass surgery 19 year ago. In the coronary care unit, the ECG showed complete left bundle branch block and subacute myocardial infarction (creatine kinase 3903 U/1) was diagnosed. Because of the time delay, no thrombolysis was given but the patient received tirofiban and heparin until
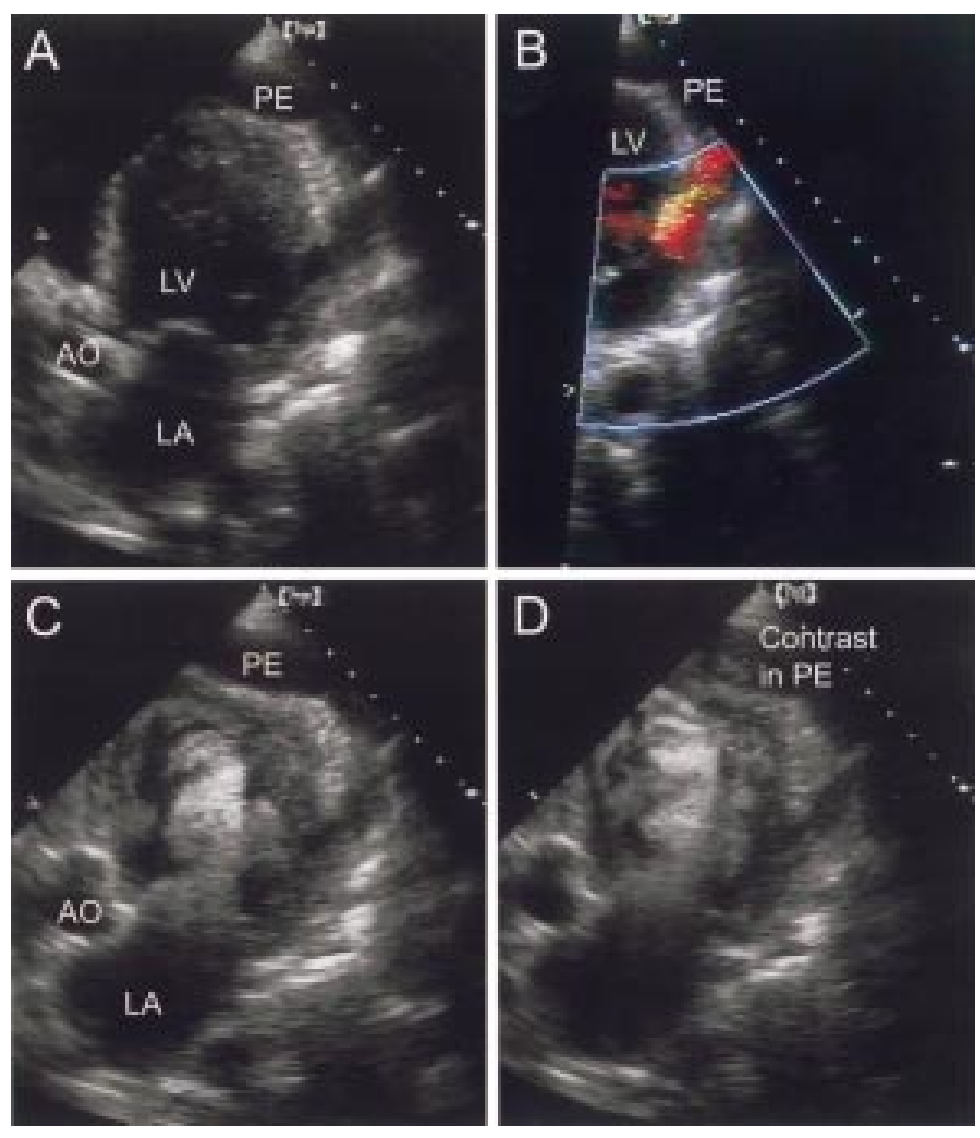

the next day when coronary angiography was performed. All bypasses were open and all major native vessels occluded, so coronary angioplasty was not feasible.

Four days later, while taking a shower on the ward, the patient suddenly experienced a severe pain in her left flank. Left heart failure developed (no new creatine phosphokinase rise occurred). Subsequent echocardiography showed myocardial rupture (maximal diameter of entry $1.5 \mathrm{~cm}$ ) of the hypokinetic inferolateral wall with effusion contained by the pericardium (pseudoaneurysm formation) as shown: A, apical long axis view showing rupture site of the inferolateral wall with pericardial effusion (PE, pericardial effusion; AO, aorta; LA, left atrium; LV, left ventricle); $\mathrm{B}$, colour Doppler flow image showing blood flow from the left ventricle through the rupture site into the pseudoaneurysm or pericardial effusion, respectively; C, immediately after intravenous contrast injection, the left ventricular cavity is filled with contrast; D, within one minute after contrast injection, contrast enhancement is seen within the pericardial effusion.

Cardiac surgery was refused by the patient. After seven days the echocardiographic findings were unchanged. Twelve days later the patient went home.

Myocardial rupture is a known fatal complication of myocardial infarction occurring especially in women, elderly patients and in first or inferior myocardial infarction. Left ventricular pseudoaneurysms form when myocardial rupture is contained by adherent pericardium or scar tissue. Free intrapericardial rupture usually results in cardiac tamponade and death. Because of this patient's previous bypass surgery there were pericardial adhesions and so the rupture was contained, which enabled pseudoaneurysm formation and thus survival.

A MENICONI C H ATTENHOFER JOST R JENNI 